\title{
Long-Term Effect of Endoscopic Sympathetic Nerve Reconstruction for Side Effects after Endoscopic Sympathectomy
}

\author{
Tuomo Rantanen ${ }^{1}$ Timo Telaranta ${ }^{2}$ \\ ${ }^{1}$ Department of Surgery, Kuopio University Hospital, Kuopio, Finland \\ 2 Privatix Clinic, Tampere, Finland \\ Address for correspondence Tuomo Rantanen, MD, PhD, Department \\ of Surgery, Kuopio University Hospital, Box 100, Kuopio 70029 KYS, \\ Finland (e-mail: tuomora@gmail.com). \\ Thorac Cardiovasc Surg 2017;65:484-490.
}

\begin{abstract}
Keywords

- endoscopic thoracic sympathectomy

- side effects

- sympathetic nerve reconstruction

- long-term results after ETS, and after SNR. situation had deteriorated.

\section{Introduction}

Although endoscopic thoracic sympathectomy (ETS) has been an accepted treatment for primary hyperhidrosis, compensatory sweating (CS) is reported to occur in 68 to $99 \%$ of the patients after ETS. ${ }^{1-4}$ In 13 to $55.9 \%$ of the cases, the CS is reported as strong or very strong. ${ }^{1,3,4}$ In $43.3 \%$ of the patients, CS caused limitations in patients' daily lives. ${ }^{3}$ At least those patients whose CS is severe or very severe should be regarded as candidates for some kind of treatment for CS. However, no report exists dealing with the exact number of patients who have been treated medically or surgically for CS.
\end{abstract}

Background Endoscopic thoracic sympathectomy (ETS) is an effective treatment for primary hyperhidrosis. However, compensatory sweating (CS) may occur in many patients. Sympathetic nerve reconstruction (SNR) can be used to counteract severe $\mathrm{CS}$, but the studies on the effects of SNR are few.

Patients and Methods Nineteen out of 150 SNR patients were contacted by employing a long-term questionnaire. In this questionnaire, different kinds of sweating were evaluated using a four-graded symptom analysis and the visual analog scale before ETS,

Results The mean age of the 16 male and 3 female patients at the SNR was 32 years. The mean follow-up was 87 months. According to the long-term questionnaire, the benefit was either excellent (4 patients, $21 \%$ ), good ( 3 patients, $15.8 \%$ ), or reasonable ( 7 patients, $36.8 \%$ ) in 14 patients $(73.8 \%)$, while the benefit was questionable in 1 patient (5.3\%). For three patients (15.8\%), no benefit was found, and in one patient (5.3\%), the

Conclusions Improvement in the side effects of ETS after SNR was found in nearly 75\% of the patients. This indicates that SNR can be considered as an alternative treatment for patients with severe CS after ETS that is unresponsive to conservative treatment. received

February 18, 2016

accepted after revision

March 7, 2016

published online

May 5, 2016

The conservative treatment methods for CS related to ETS include the use of anticholinergic agents administered either locally or orally, ${ }^{5,6}$ botulinum toxin, ${ }^{7}$ or regional abdominolumbar iontophoresis (RALI). ${ }^{8}$

When conservative treatment after ETS fails, the only method is surgical sympathetic nerve reconstruction (SNR) using either a sural ${ }^{9}$ or an intercostal nerve graft. ${ }^{10}$ There are only a few studies reporting the results of SNRs, one of which is a case report. ${ }^{9}$ Not only the reports on SNR are few but also the long-term results after SNR are even more scarce. Therefore, we conducted the present study and report our longterm results of SNR.

(c) 2017 Georg Thieme Verlag KG Stuttgart · New York
DOI https://doi.org/ 10.1055/s-0036-1582431. ISSN 0171-6425. 


\section{Patients and Methods}

\section{Study Population}

Records on 150 patients treated for severe side effects of ETS with SNR were reviewed retrospectively. The inclusion criteria for participation in the study were successfully performed SNR and response to the long-term follow-up questionnaire. To the patients who did not respond to the first questionnaire sent via e-mail, the questionnaire was resent two more times (three questionnaires/patient). To those patients whom the questionnaire was sent by regular post, it was posted only once because the addresses proved incorrect in all cases. For the Japanese patients, the questionnaire was translated into Japanese, but for all other patients, the questionnaire was written in English.

For $16(10.7 \%)$ patients, SNR could not be performed adequately, and they were therefore excluded. In four of them, the planned procedure could not be performed due to severe adhesions (two patients) or too many sympathetic ganglia destroyed in the primary operation ( $>3$ ganglia when intercostal nerve was used as a nerve graft; two patients). The latter situation made the operation impossible because the nerve graft was not long enough for reconstruction. In addition, in 12 cases, the third or fourth intercostal nerve could be connected only to the proximal part of the sympathetic nerve without connecting it to the distal part of the sympathetic nerve. In these cases, no sympathetic nerve connection was achieved below the third or fourth sympathetic ganglion.

Nineteen patients responded to the long-term follow-up questionnaire and these results were analyzed.

\section{Surgical Procedure}

The surgical procedure was conducted using a video-assisted thoracoscopic technique under a single-lumen tube general anesthesia. The patients were placed supinely with both arms abducted. Two intercostal ports between the third and fifth ribs were used to gain access to the chest. A third, anteriorly placed port was applied when needed. The procedure was started on the right side. After $\mathrm{CO}_{2}$ gas insufflation into the thoracic cavity with less than $12 \mathrm{~mm} \mathrm{Hg}$ of pressure to deflate lung, the pleural space was inspected using a 7 to $10 \mathrm{~mm}$ thoracoscope, and pleural adhesions were cut when needed. The proximal and distal parts of the previously operated sympathetic nerve were exposed and cut to get florid ends of the nerve. Either the sural or the intercostal nerve was used as a free graft in the original direction; it was placed between the proximal and distal parts of the exposed sympathetic nerve, and fibrin glue was applied onto the contact surfaces of the sympathetic and the sural or intercostal nerve. The intercostal nerve was harvested using the same ports during thoracoscopy. The pleural space was opened below the costal margin, and third or fourth intercostal nerve was dissected free laterally as much as needed. The required length of intercostal nerve was evaluated using a dissector in an open position. When adequate length of intercostal nerve was achieved, it was cut both laterally and medially. When the sural nerve was used, a 20 to $30 \mathrm{~cm}$ segment of the sural nerve was harvested from either the left or right calf using two or three small incisions. The sural nerve was used in the first 50 cases and, thereafter, the intercostal nerve was applied. The main reason for the use of the intercostal nerve was that it could be taken using the same ports that were employed in the operation itself.

\section{Data Collection}

The 19 patients who responded to the long-term follow-up questionnaire were asked about the following aspects: sex, age at ETS and SNR as well as at the time of filling in the questionnaire, and the reason(s) for ETS. In addition, the following psychological and physical symptoms were analyzed and scored from 1 to 4 ( $1=$ normal, $2=$ mild, $3=$ moderate, and $4=$ severe) before ETS, after ETS, and at 3, 6, and 12 months after SNR as well as at the time of taking the questionnaire: hand sweating (HSW), facial sweating (FSW), underarm sweating (USW), general sweating (GSW), blushing, social phobia, and trembling of the hands. We have also used these symptom-analysis methods previously, and they are included in Davidson's Brief Social Phobia Scale and the Leibovitz Quality of Life Scale. ${ }^{11-13}$ In addition, fatigue (none, mild, moderate, or severe) and energy level (normal, mildly lowered, moderately lowered, or severely lowered) after ETS and SNR were analyzed. Finally, the visual analog scale (VAS) $(0=$ best possible situation and $100=$ worst possible situation $)^{14}$ was recorded before ETS, after ETS, and at the time of taking the questionnaire after SNR, concerning the following symptoms: HSW, FSW, USW, GSW, blushing, social phobia, trembling of the hands, and gustatory sweating. Finally, the same VAS was used to analyze general well-being before ETS, after ETS, and after SNR.

In addition, the ganglia destroyed during ETS, the upper and lower ganglia between which the SNR was performed, and the interval between ETS and SNR were identified. Finally, the used nerve graft (either sural or intercostal) was identified.

\section{Evaluation of Data}

The definition of the benefit of SNR is shown in - Table 1.

In brief, the benefit was determined using the effect of SNR on CS, energy level, and general well-being after SNR.

\section{Statistics}

The chi-square test was used for statistical comparisons between the results of the sural and intercostal nerve, between the number of destroyed ganglia (one vs. more), and between the short (maximum of 12 months) and long (> 12 months) intervals from ETS to SNR. A $p<0.05$ was considered as statistically significant.

\section{Ethics}

This study was approved by the Ethical Committee of Sympatix Clinique.

\section{Results}

The mean age of 16 male and 3 female patients at the time of SNR was 32 years (16-49 years). The mean interval between 
Table 1 Definition of the benefit of SNR

\begin{tabular}{|l|}
\hline Excellent benefit \\
\hline $\begin{array}{l}\text { Significant decrease in CS (VAS value diminished by at least 40) and either significant increase in energy level } \\
\text { (at least two grades) or significant improvement in general well-being (numerical value diminished by at least 40) }\end{array}$ \\
\hline CS normalized \\
\hline Good benefit \\
\hline Significant decrease in CS \\
\hline Significant increase in energy level \\
\hline Significant improvement in general well-being \\
\hline Energy level normalized without significant decrease in CS \\
\hline Reasonable benefit \\
\hline Moderate decrease in CS (at least 20) \\
\hline Minor decrease in CS (at least 10) and minor increase in energy level (at least one grade) \\
\hline Questionable benefit \\
\hline Minor decrease in CS (at least 10) \\
\hline Minor increase in energy level (at least one grade) \\
\hline Negative benefit \\
\hline No changes in CS, energy level, and general well-being \\
\hline
\end{tabular}

Abbreviations: CS, compensatory sweating; SNR, sympathetic nerve reconstruction; VAS, visual analog scale.

the ETS and SNR was 39 months (6-144 months). The mean follow-up time was 87 months (6-180 months). For all of these 19 patients, the SNR could be performed as planned.

The primary reason for ETS was HSW in eight, blushing (associated with HSW in one and both FSW and HSW in one) in six, FSW in two, FSW and HSW in two, and USW in one case. The destroyed ganglia, the interval between ETS and SNR, the nerve graft applied, and the benefit of SNR are shown in - Table 2.

Among the 19 patients who responded to the long-term follow-up questionnaire, the benefit was either excellent (4 patients, $21 \%$ ), good ( 3 patients, $15.8 \%$ ), or reasonable ( 7 patients, $36.8 \%$ ) in 14 patients $(73.7 \%)$, while the benefit was questionable in 1 patient (5.3\%). For three (15.8\%) patients, there was no benefit, and one patient (5.3\%) found the situation after the SNR worse (permanent Horner syndrome). The energy level or fatigue had improved in 11 out of the 19 patients (57.9\%), with a severely lowered energy level having normalized in four patients (36.4\%) and moderate fatigue in one patient $(9.1 \%)$. The reasons for excellent or good benefit among patients with the longterm questionnaire are presented in - Table 3.

Excellent or good benefit was found more often when an intercostal nerve graft was used $(81.8 \%)$ as opposed to the sural nerve (62.5\%), and when only one ganglion had been destroyed as opposed to several destroyed ganglia (80 vs. $69 \%$ ). Similarly, excellent or good benefit was more likely with a short interval between ETS and SNR as opposed to a long one ( 80 vs. $72.7 \%$ ). However, no statistically significant differences were found in any of these three parameters. This is probably due to the small number of patients in the different categories.
According to the results of our long-term questionnaire, the primary symptom(s) that had led to ETS did not recur after SNR. Fate of HSW, FSW, blushing, and social phobia, which were the primary reasons for ETS, are shown in -Tables $\mathbf{4}$ and $\mathbf{5}$.

There was one (5.3\%) complication after SNR among the 19 patients included. This patient developed permanent Horner syndrome.

\section{Comment}

Our results from the long-term questionnaire show that approximately $75 \%$ of the patients benefited from SNR after a mean of 87 months and that in seven (50\%) of these, the improvement was significant. In most of the patients with significant improvement in side effects, the general wellbeing improved as well. This indicates that SNR can be considered as a potential treatment option for patients with severe side effects from ETS which are unresponsive to conservative treatment.

To diminish the occurrence and severity of CS after ETS, endoscopic sympathetic block (ESB) was developed. ${ }^{15}$ However, the occurrence of CS between ESB and ETS is controversial, some authors reporting adverse effects to be less frequent after $\mathrm{ESB}^{15,16}$ than after ETS, while some studies ${ }^{17,18}$ have not found any differences in the occurrence of CS. Therefore, the selection of the lowest effective level of sympathectomy may be more important than the method used to diminish severe adverse effects after these procedures. ${ }^{18-20}$ However, only ESB is thought to be a reversible operation if severe CS develops. This means that unclipping is possible only after ESB, and it is the primary method after ESB when too severe CS is encountered. The 
Table 2 Destroyed ganglia in ETS, mean interval (months) between ETS and SNR, the nerve graft used, and the benefit of SNR in 19 patients

\begin{tabular}{|c|c|c|c|c|}
\hline $\begin{array}{l}\text { Patient } \\
\text { number }\end{array}$ & $\begin{array}{l}\text { Destroyed } \\
\text { ganglia }\end{array}$ & $\begin{array}{l}\text { Interval between } \\
\text { ETS and SNR }\end{array}$ & Graft & Benefit of SNR \\
\hline 1 & $\mathrm{~T} 2, \mathrm{~T} 3$ & 29 & $S$ & Worsening \\
\hline 2 & $\mathrm{~T} 2, \mathrm{~T} 3$ & 24 & $S$ & Good \\
\hline 3 & T2,T3,Т4,T5 & 48 & $S$ & Good \\
\hline 4 & $\mathrm{~T} 2, \mathrm{~T} 3$ & 48 & $S$ & Excellent \\
\hline 5 & $\mathrm{~T} 3, \mathrm{~T} 4$ & 12 & $S$ & Negative \\
\hline 6 & $\mathrm{~T} 3, \mathrm{~T} 4$ & Unknown & $\mathrm{S}$ & Negative \\
\hline 7 & $\mathrm{~T} 3$ & 12 & $S$ & Excellent \\
\hline 8 & T3 & Unknown & $S$ & Good \\
\hline 9 & $\mathrm{~T} 3, \mathrm{~T} 4$ & 168 & IC & Questionable \\
\hline 10 & T3 & 84 & IC & Excellent \\
\hline 11 & T3 & 96 & IC & Negative \\
\hline 12 & $\mathrm{~T} 2$ & Unknown & IC & Good \\
\hline 13 & $\mathrm{~T} 2, \mathrm{~T} 3$ & 24 & IC & Excellent \\
\hline 14 & $\mathrm{~T} 2, \mathrm{~T} 3$ & 48 & IC & Good \\
\hline 15 & $\mathrm{~T} 3, \mathrm{~T} 4$ & 8 & IC & Good \\
\hline 16 & $\mathrm{~T} 3, \mathrm{~T} 4$ & 36 & IC & Excellent \\
\hline 17 & $\mathrm{~T} 3, \mathrm{~T} 4$ & 6 & IC & Good \\
\hline 18 & $\mathrm{~T} 2, \mathrm{~T} 3, \mathrm{~T} 4$ & 12 & IC & Excellent \\
\hline 19 & T3 & 120 & IC & Good \\
\hline
\end{tabular}

Abbreviations: ETS, endoscopic thoracic sympathectomy; S, sural nerve; IC, intercostal nerve; SNR, sympathetic nerve reconstruction.

Table 3 Reasons for excellent (four patients) or good ${ }^{3}$ benefit in seven patients who completed the long-term questionnaire

\begin{tabular}{|c|c|c|c|}
\hline \multicolumn{4}{|c|}{ Excellent benefit } \\
\hline \multirow[t]{4}{*}{ Patient 1} & EL normalized & \multirow[t]{4}{*}{ Patient 2} & EL normalized \\
\hline & GSW from 100 to 60 & & GSW from 80 to 20 \\
\hline & GUSW from 70 to 20 & & GUSW from 60 to 30 \\
\hline & GWB from 90 to 20 & & GWB from 90 to 30 \\
\hline \multirow[t]{4}{*}{ Patient 3} & EL normalized & \multirow[t]{4}{*}{ Patient 4} & Fatigue normalized \\
\hline & GSW from 100 to 60 & & EL normalized \\
\hline & GWB from 100 to 20 & & GSW from 100 to 60 \\
\hline & & & GWB from 90 to 20 \\
\hline \multicolumn{4}{|c|}{ Good benefit } \\
\hline \multirow[t]{3}{*}{ Patient 1} & EL normalized & \multirow[t]{3}{*}{ Patient 2} & GSW from 70 to 30 \\
\hline & GSW from 80 to 70 & & GUSW from 100 to 50 \\
\hline & & & GWB from 90 to 30 \\
\hline \multirow[t]{3}{*}{ Patient 3} & GSW from 90 to 30 & & \\
\hline & GUSW from 40 to 20 & & \\
\hline & GWB from 100 to 20 & & \\
\hline
\end{tabular}

Abbreviations: CS, compensatory sweating; EL, energy level; GSW, general sweating; GUSW, gustatory sweating; GWB, general well-being. 
Table 4 Fate of HSW (11 patients) and FSW (4 patients) that led to ETS

\begin{tabular}{|l|l|l|l|}
\hline HSW & Before ETS & After ETS & After ETS reversal \\
\hline Patient 1 & 70 & 0 & 20 \\
\hline Patient 2 & 80 & 10 & 0 \\
\hline Patient 3 & 70 & 100 & 20 \\
\hline Patient 4 & 80 & 30 & 30 \\
\hline Patient 5 & 100 & 20 & 20 \\
\hline Patient 6 & 50 & 50 & 30 \\
\hline Patient 7 & 70 & 100 & 0 \\
\hline Patient 8 & 90 & 10 & 0 \\
\hline Patient 9 & 80 & 50 & 10 \\
\hline Patient 10 & 80 & 0 & 0 \\
\hline Patient 11 & 60 & 10 & 20 \\
\hline FSW & Before ETS & After ETS & After ETS reversal \\
\hline Patient 1 & 80 & 0 & 10 \\
\hline Patient 2 & 80 & 100 & 100 \\
\hline Patient 3 & 80 & 0 & 0 \\
\hline Patient 4 & 70 & 10 & 30 \\
\hline
\end{tabular}

Abbreviations: ETS, endoscopic thoracic sympathectomy; FSW, facial sweating; HSW, hand sweating.

Notes: One patient could have many symptoms before ETS. Figures derived with the visual analog scale $(0=$ the best possible situation and $100=$ the worst possible situation).

unclipping should be performed during the first month, since according to animal models, permanent damage occurs by the 30th day. ${ }^{21}$ This is also our policy when too severe CS after ESB is encountered. ${ }^{11}$ In the study by Lin et $\mathrm{al}^{15}$ up to $80 \%$ of the

Table 5 Fate of blushing (six patients) and social phobia (four patients) that led to ETS

\begin{tabular}{|l|l|l|l|}
\hline Blushing & Before ETS & After ETS & $\begin{array}{l}\text { After ETS } \\
\text { reversal }\end{array}$ \\
\hline Patient 1 & 100 & 30 & 30 \\
\hline Patient 2 & 100 & 0 & 0 \\
\hline Patient 3 & 60 & 30 & 0 \\
\hline Patient 4 & 100 & 50 & 40 \\
\hline Patient 5 & 90 & 30 & 40 \\
\hline Patient 6 & 100 & 30 & 30 \\
\hline Social phobia & Before ETS & After ETS & $\begin{array}{l}\text { After ETS } \\
\text { reversal }\end{array}$ \\
\hline Patient 1 & 80 & 70 & 20 \\
\hline Patient 2 & 100 & 50 & 40 \\
\hline Patient 3 & 60 & 60 & 30 \\
\hline Patient 4 & 80 & 10 & 30 \\
\hline
\end{tabular}

Abbreviation: ETS, endoscopic thoracic sympathectomy.

Notes: One patient could have many symptoms before ETS. Figures derived with the visual analog scale $(0=$ the best possible situation and $100=$ the worst possible situation). unclipped patients recovered after the second procedure. In the study by Sugimura et al, ${ }^{16} 48 \%$ of the unclipped patients reported a substantial decrease in their CS. In the early (unclipping before 6 months after ESB) and the late groups (unclipping after 6 months), 67 and 37\%, respectively, of the unclipped patients reported a substantial decrease in their CS.

In the study by Stefaniak et al, ${ }^{8} 47 \%$ of the patients reported a reduction in CS after unclipping, but these patients declared an increase in their overall sense of illness, probably because they experienced the recurrence of their initial suffering. The new operation in the study by Stefaniak et $\mathrm{al}^{8}$ included bothsided T6-9 block. This resulted in partial and transient, nonsignificant diminishing of the symptom. RALI resulted in the most immediate and sustained $43.5 \%$ reduction in CS, but it demands repeated procedures and can lead to burns that heal slowly. ${ }^{8}$ Our results after SNR compared favorably with the above-mentioned results-in fact, they performed somewhat better. However, SNR is more invasive and demanding than other treatment methods for CS. All conservative methods should therefore be exhausted before SNR is considered. Conservative methods include the reduction of overweight, topical application of aluminum salts, a subcutaneous injection of botulinum toxin, and orally administered anticholinergic medications including glycopyrrolate and oxybutynin. A topically applicated form of glycopyrrolate is also available.

Although the most frequent severe adverse effect after a sympathetic procedure is CS, there are also other complaints, including gustatory sweating, loss of energy level, and fatigue. In the present study, the energy level increased or fatigue decreased in $57.9 \%$ of the patients after the SNR according to the long-term questionnaire. In fact, in $45.5 \%$ of the questionnaire respondents, the energy level or fatigue normalized. To our knowledge, this is the first study reporting the effect of SNR on energy level.

Our success rate was somewhat better than the one reported in the study by Haam et al. ${ }^{10}$ Approximately $75 \%$ of our patients benefited from SNR, while the corresponding figure in the study by Haam et $\mathrm{al}^{10}$ was $52 \%$. We used a free sural or intercostal nerve graft in the original direction, while Haam et a ${ }^{10}$ applied a pedicled intercostal nerve graft in the reverse direction. This may have influenced the differences between our results and those of Haam et al. ${ }^{10}$ Another difference between our study and the study by Haam et $\mathrm{a}^{10}$ was that all of our operated patients had undergone an ETS procedure, while 4 of the 19 (21\%) patients in the study by Haam et $\mathrm{al}^{10}$ had previously undergone an ESB procedure. We have also performed reversal operations on some ESB-operated patients in our earlier series, but our results have not been encouraging (data not presented). However, $75 \%$ of the previously ESB-operated patients in the study by Haam et $\mathrm{al}^{10}$ benefited from SNR. Therefore, this aspect seems not to be very important in explaining the detected differences between our study and the study by Haam et al. ${ }^{10}$ We have only one patient who developed the Horner syndrome. Due to extensive scarring, we tried to go as high as up to the fresh nerve, which in such cases is very near to the Th I ganglion. In the case with Horner sign, we just have approached the critical point in the sympathetic chain too closely. 
Although most of our patients experienced some relief after SNR, for some the SNR had no effect on the side effects suffered after ETS. The reasons for this are unknown. Possible explanations include a too long interval between the ETS and SNR, too heavy adhesions after ETS, and too extensive nerve damage in the primary ETS procedure leading to a long bypass operation. Finally, the nerve graft selected (sural or intercostal nerve) may have influenced this phenomenon. In most of the cases, the operative documents could not be found. This makes it impossible to check the above-mentioned aspects. However, in most of the 19 patients who responded to the long-term questionnaire, the number of destroyed ganglia in ETS, the interval between ETS and SNR, as well as the nerve graft used could be identified. Although we found clinically significant differences in certain of the above-mentioned aspects favoring an intercostal nerve graft, only one destroyed ganglion in the primary operation and a short interval between ETS and SNR, no statistically significant differences were found. This was probably due to the small number of patients in the different categories. The intercostal nerve is easy to harvest at the same pot as the lesion and its quality are better due to its tenacity and rounder form than the sural nerve. It also has clearly less side effects: only an insignificant slight transient paresthesia on the flank. In some cases, it can even be used as a vascular pedicled graft.

Some patients redevelop their primary symptoms after unclipping, and this may be the main reason for dissatisfaction after unclipping, although the side effects are diminished. In the study by Sugimura et $\mathrm{al}^{16}$ control of the hyperhidrosis or blushing was well maintained in 25 and $53 \%$ of the early and late groups, respectively. Some patients may indeed have the fear after SNR that their primary symptom(s) will recur while the CS and other side effects improve. In the present study, we did not find such an effect in the long-term questionnaire group, since their blushing, FSW, HSW, or social phobia did not return. The most probable cause for this is our surgical method, in which the previously destroyed ganglia were bypassed. However, some patients found that their hands were sweating to a degree during exercise (data not presented), whereas before the SNR, they had been too dry. This was observed in the VAS scores where the patients with dry hands gave the worst value before SNR and reported no more problems with their hands afterward. However, some patients still had dry hands after SNR, and in such cases, the VAS values were still the worst possible.

Our study has several limitations. The most important one is that we could reach only 19 out of 150 (12.7\%) patients, which can cause bias. However, dropouts occurred unselectively and the backgrounds of included and excluded cases did not differ from each other. In addition, among 45 patients whose results were obtained from other datasets previously (27 patients with another questionnaire and 18 with a free-form e-mail message), the results were similar when compared with those obtained with our long-term questionnaire (data not presented). These results are in line with our perception on what the results of SNR at our clinic are. However, we could not use these 45 patients in the analysis due to different datasets because this could have caused bias. The patients were operated on at various private clinics during the time when patient records were, in most of the cases, destroyed. This was probably the most important factor for dropouts. In addition, after a long period, the patients' addresses (e-mail, postal) had changed in many cases and we could not locate them. In addition, our long-term questionnaire was retrospective, which may have prevented us from identifying some important aspects. Finally, our long-term questionnaire was translated only into English and Japanese, which may have caused some bias related to understanding the questions and may be one reason for the quite low response rate. However, the questions were made as simple as possible to be better understandable. A positive sign is that the questionnaire was compiled and the follow-up survey performed by an independent person was not involved in the patients' care.

In conclusion, we found improvement in the side effects of ETS after SNR in $75 \%$ of the evaluated patients in the long term. For $50 \%$ of these, the improvement was remarkable. This indicates that SNR can be considered as an alternative treatment option for patients with severe side effects from the ETS procedure that are unresponsive to conservative treatment. A prospective study remains to be performed to identify the risk factors for the worse than expected results of SNR in some patients.

\section{Disclosure}

The authors have no conflict of interest or financial ties to disclose.

\section{References}

1 Jadresic E, Súarez C, Palacios E, Palacios F, Matus P. Evaluating the efficacy of endoscopic thoracic sympathectomy for generalized social anxiety disorder with blushing complaints: a comparison with sertraline and no treatment-Santiago de Chile 2003-2009. Innov Clin Neurosci 2011;8(11):24-35

2 Coveliers H, Atif S, Rauwerda J, Wisselink W. Endoscopic thoracic sympathectomy: long-term results for treatment of upper limb hyperhidrosis and facial blushing. Acta Chir Belg 2011;111(5): 293-297

3 Smidfelt K, Drott C. Late results of endoscopic thoracic sympathectomy for hyperhidrosis and facial blushing. Br J Surg 2011;98(12): 1719-1724

4 Bachmann K, Standl N, Kaifi J, et al. Thoracoscopic sympathectomy for palmar and axillary hyperhidrosis: four-year outcome and quality of life after bilateral 5-mm dual port approach. Surg Endosc 2009;23(7):1587-1593

5 Costa AdaS Jr, Leão LE, Succi JE, et al. Randomized trial - oxybutynin for treatment of persistent plantar hyperhidrosis in women after sympathectomy. Clinics (Sao Paulo) 2014;69(2): 101-105

6 Gong TK, Kim W. Effectiveness of oral glycopyrrolate use in compensatory hyperhidrosis patients. Korean J Pain 2013;26(1): 89-93

7 Santana-Rodríguez N, Clavo B, Calatayud-Gastardi J, et al. Severe compensatory hyperhidrosis following thoracic sympathectomy successfully treated with low doses of botulinum toxin A. J Dermatolog Treat 2012;23(6):457-460

8 Stefaniak T, Cwigon M, taski D. In the search for the treat ment of compensatory sweating. Sci World J 2012;2012: 134547

9 Telaranta T. Secondary sympathetic chain reconstruction after endoscopic thoracic sympathicotomy. Eur J Surg Suppl 1998; 580(580):17-18 
10 Haam SJ, Park SY, Paik HC, Lee DY. Sympathetic nerve reconstruction for compensatory hyperhidrosis after sympathetic surgery for primary hyperhidrosis. J Korean Med Sci 2010;25(4):597-601

11 Rantanen T, Telaranta T. Long-term results of endoscopic sympathetic block using the Lin-Telaranta classification. Surg Endosc 2013;27(10):3860-3864

12 Davidson JR, Miner CM, De Veaugh-Geiss J, Tupler LA, Colket JT, Potts NL. The brief social phobia scale: a psychometric evaluation. Psychol Med 1997;27(1):161-166

13 Taiminen T. Sosiaalisten tilanteiden pelon hoito [in English]. Duodecim 1998;114(1):73-79

14 Reading A. Testing pain mechanisms in persons in pain. In: Wall P, Melzack R, eds. Textbook of Pain. 2nd ed. New York: Churchill Livingstone Inc; 1989:269-280

15 Lin CC, Mo LR, Lee LS, Ng SM, Hwang MH. Thoracoscopic T2sympathetic block by clipping-a better and reversible operation for treatment of hyperhidrosis palmaris: experience with 326 cases. Eur J Surg Suppl 1998;580(580):13-16

16 Sugimura H, Spratt EH, Compeau CG, Kattail D, Shargall Y. Thoracoscopic sympathetic clipping for hyperhidrosis: long-term results and reversibility. J Thorac Cardiovasc Surg 2009;137(6): 1370-1376, discussion 1376-1377

17 Coelho MdeS, Silva RF, Mezzalira G, et al. T3T4 endoscopic sympathetic blockade versus T3T4 video thoracoscopic sympathectomy in the treatment of axillary hyperhidrosis. Ann Thorac Surg 2009; 88(6):1780-1785

18 Yanagihara TK, Ibrahimiye A, Harris C, Hirsch J, Gorenstein LA. Analysis of clamping versus cutting of $\mathrm{T} 3$ sympathetic nerve for severe palmar hyperhidrosis. J Thorac Cardiovasc Surg 2010; 140(5):984-989

19 Neumayer C, Zacherl J, Holak G, et al. Limited endoscopic thoracic sympathetic block for hyperhidrosis of the upper limb: reduction of compensatory sweating by clipping T4. Surg Endosc 2004; 18(1):152-156

20 Reisfeld R. Sympathectomy for hyperhidrosis: should we place the clamps at T2-T3 or T3-T4? Clin Auton Res 2006;16(6): 384-389

21 Loscertales J, Congregado M, Jimenez-Merchan R, et al. Sympathetic chain clipping for hyperhidrosis is not a reversible procedure. Surg Endosc 2012;26(5):1258-1263 